\title{
Parâmetros citológicos e bioquímicos do líquido cefalorraquidiano coletado de bovinos sadios em dois momentos, com intervalo de 96 horas
}

\author{
[Cerebrospinal fluid cytological and biochemical values of healthy cattle in two \\ sampling times with an interval of 96 hours] \\ P.H.J. Cunha ${ }^{1}$, D.G.A. Andrade ${ }^{2}$, J.P. Oliveira-Filho ${ }^{2}$, P.R. Badial ${ }^{2,3}$, D. Passarelli ${ }^{2,4}$, \\ R.K. Takahira ${ }^{2}$, J.A.N. Lisboa ${ }^{5}$, A.S. Borges ${ }^{2}$ \\ ${ }^{1}$ Escola de Veterinária e Zootecnia - Universidade Federal de Goiás - Goiânia, GO \\ ${ }^{2}$ Faculdade de Medicina Veterinária e Zootecnia, UNESP - Universidade Estadual Paulista - Botucatu, SP \\ ${ }^{3}$ College of Veterinary Medicine - Mississippi State University - Mississippi State, MS, USA \\ ${ }^{4}$ Faculdade de Zootecnia e Engenharia de Alimentos - Universidade de São Paulo - Pirassununga, SP \\ ${ }^{5}$ Centro de Ciências Agrárias - Universidade Estadual de Londrina - Londrina, PR
}

\begin{abstract}
RESUMO
A análise do líquido cefalorraquidiano (LCR) é uma importante ferramenta no diagnóstico das doenças neurológicas dos bovinos. A coleta do LCR em diferentes momentos facilita o monitoramento do quadro clínico e/ou a avaliação da eficácia de tratamentos estabelecidos. Todavia, os efeitos de coletas consecutivas sobre os parâmetros citológicos e bioquímicos do LCR de bovinos saudáveis ainda não foram analisados. Dessa forma, o objetivo do presente estudo foi avaliar potenciais diferenças citológicas e bioquímicas no LCR de bovinos sadios, obtidos em dois momentos, com intervalo de 96 horas. O LCR foi submetido à análise citológica e à determinação do teor de proteína total. Na segunda coleta, verificou-se aumento significativo da celularidade, porém ainda dentro do intervalo de referência para a espécie, diminuição de linfócitos e elevação de células mononucleares em relação à primeira coleta. No entanto, os números de hemácias $(/ \mu \mathrm{L})$, células nucleadas $(/ \mu \mathrm{L})$, neutrófilos $(\%)$, eosinófilos $(\%)$ e a concentração da proteína total $(\mathrm{mg} / \mathrm{dL})$ continuaram dentro dos valores de referência 96 horas após a realização da primeira punção. Conclui-se que os procedimentos de coleta de LCR consecutivos não provocaram inflamação local detectável 96 horas após a primeira punção, o que sugere que, quando necessário, coletas de LCR seriadas, por si só, não interfeririam nos resultados do exame.
\end{abstract}

Palavras-chave: bovinos, líquido cefalorraquidiano, inflamação

\begin{abstract}
The analysis of cerebrospinal fluid (CSF) is important for the diagnosis of neurological diseases in cattle. However, the effect of consecutive collections on the cytological and biochemical parameters of the CSF has not been evaluated yet. The objective of the present study was to evaluate potential differences on the cytological and biochemical analysis of CSF obtained from healthy cattle at two sampling times with 96 hours of interval in between. Total and differential cell counts, and total protein concentration were analyzed in the CSF. Increased cellularity and significant reduction of lymphocyte and elevated numbers of mononuclear cells were observed on the second collection. However, erythrocyte count $(/ \mu l)$, total

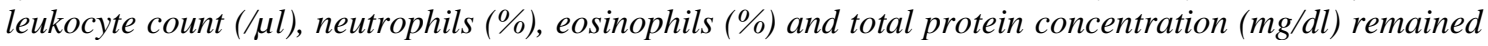
within the reference range 96 hours after the completion of the first puncture. In conclusion, consecutive CSF collections cause no detectable local inflammation 96 hours after the first puncture suggesting that repeated collections do not interfere in the CSF results.
\end{abstract}

Keywords: cattle, cerebrospinal fluid, inflammation

Recebido em 31 de agosto de 2016

Aceito em 3 de fevereiro de 2017

E-mail: phcunhavet@yahoo.com.br 


\section{Cunha et al.}

\section{INTRODUÇÃO}

A análise do líquido cefalorraquidiano (LCR) é um exame complementar útil e rápido para o diagnóstico etiológico das doenças do sistema nervoso central (SNC). A contagem total e diferencial das células e a concentração de proteína total podem fornecer informações para detecção de alterações inflamatórias, a fim de confirmar a existência de anormalidade neurológica e, em alguns casos, definir a etiologia do processo (St. Jean et al., 1997; D'Angelo et al., 2009; Kumar e Kumar, 2012; Bellino et al., 2015; Braun e Attiger, 2016). Em bovinos, a evolução de determinadas encefalopatias proporciona a coleta do LCR em diferentes momentos, tornando possível monitorar o quadro clínico e/ou avaliar a eficácia do tratamento estabelecido (Stokol et al., 2009).

Apesar de as pesquisas avaliarem a composição do LCR em bovinos clinicamente saudáveis imediatamente após (Welles et al., 1992) ou 24 horas após a coleta (D'Angelo et al., 2009) e em animais com diferentes neuropatias (Stokol et al., 2009), não existem, na literatura compilada, estudos que detectaram o efeito de coletas seriadas sobre os resultados laboratoriais do LCR. Portanto, o objetivo do presente trabalho foi verificar se a primeira coleta de LCR em bovinos clinicamente sadios interfere nos resultados das análises citológicas e bioquímicas de uma segunda amostra obtida com intervalo de 96 horas.

\section{MATERIAL E MÉTODOS}

Foram utilizados seis bovinos mestiços (dois $1 / 2$ Holandês preto e branco, dois $1 / 2$ Jersey e dois $1 / 2$ Nelore), três machos e três fêmeas, com idade média de oito meses, sendo todos eles considerados hígidos após o exame físico (Feitosa, 2014). Os animais foram mantidos em baias individuais e alimentados com capim Napier (Pennisetum purpureum) triturado, feno coast-cross (Cynodon dactylon) e água ad libitum, durante todo o período experimental.

As duas coletas de LCR (M1 e M2) foram realizadas segundo protocolo proposto por Mayhew (1989), com intervalo de 96 horas entre elas. Os animais foram submetidos à sedação com cloridrato de xilazina $\left(\right.$ Xilazin $^{\circledR}$ - Syntec Brasil) $(0,05 \mathrm{mg} / \mathrm{kg} / \mathrm{IV})$, indução anestésica com tiopental sódico (Thiopentax ${ }^{\circledR}-$ Cristália -
Brasil) $(5,0 \mathrm{mg} / \mathrm{kg} / \mathrm{IV})$, tricotomia, antissepsia com digluconato de clorexidina degermante $2 \% \mathrm{e}$ alcoólico $0,5 \%$ e punção no espaço atlantoocciptal com agulha espinhal 20Gx 31/2" (Agulha BD Spinal 20Gx31/2" - Becton Dickinson EUA).

As amostras de LCR foram coletadas em três tubos de vidro estéreis sem anticoagulante, sendo utilizada uma fração da amostra do terceiro tubo para análise do LCR. O número de leucócitos e hemácias por microlitro do LCR foi mensurado com o uso da câmara de Fuchs-Rosenthal. A contagem diferencial de leucócitos foi feita em lâminas preparadas por citocentrifugação (Citocentrífuga 2000D - Revan Instrumentos Científicos - Brasil), as quais foram coradas com panótico (Laborclin - Brasil). A concentração proteica no LCR foi mensurada com kits comerciais (Microprote - Doles - Brasil), empregando-se o método colorimétrico, cujas leituras das reações foram feitas em espectrofotômetro (De Lorenzi e Mandara, 2009). As contagens de hemácias e células nucleadas totais por microlitro, assim como as contagens diferenciais de leucócitos, foram realizadas "às cegas" por dois profissionais, que desconheciam a identificação do animal e o momento da coleta.

Estatísticas descritivas foram realizadas para todos os parâmetros laboratoriais do LCR avaliados e submetidos à análise estatística no programa GraphPad Prism 5 para Windows (GraphPad Software - EUA). O teste t pareado foi utilizado para as amostras que apresentaram distribuição normal (contagem total de células nucleadas, porcentagem de linfócitos, porcentagem de células mononucleares e concentração de proteína), e o teste de postos sinalizados de Wilcoxon para os dados não paramétricos (porcentagem de neutrófilos $\mathrm{e}$ porcentagem de eosinófilos). Diferença estatística foi considerada para $\mathrm{P} \leq 0,05$ (Sampaio, 1998).

Os animais foram avaliados clinicamente durante todo o experimento e até sete dias após a segunda coleta. Todos os procedimentos realizados encontravam-se de acordo com as normas e os princípios éticos de experimentação animal, estabelecidos pela Comissão de Ética no Uso de Animais institucional (protocolo no95/2007- Ceua). 


\section{RESULTADOS E DISCUSSÃO}

A necessidade de sedação ou de anestesia geral dos animais antes da coleta do LCR no espaço atlanto-occiptal foi reportada por Holbrook e White (1992) para a realização do procedimento de forma segura. Contudo, o uso da sedação para coleta do LCR em animais com sinais neurológicos deve ser avaliado pelo clínico, uma vez que a sedação, nesses casos, pode agravar o quadro clínico (Scott, 2004). O protocolo anestésico utilizado nos animais experimentais mostrou-se seguro e eficiente, restringindo qualquer movimento do animal durante o procedimento, o que minimizou a chance de possível contaminação do LCR com sangue durante a coleta.

O intervalo de 96 horas entre as coletas foi estabelecido pelo fato de esse ser o período normalmente utilizado pelos clínicos para realização de nova avaliação laboratorial do LCR, a fim de monitorar, de forma mais eficiente, a evolução do quadro clínico do paciente. Além disso, Stokol et al. (2009) citaram que as principais manifestações de encefalite em bovinos são causadas por infecções bacterianas, portanto o intervalo de 96 horas entre as coletas corresponde usualmente a aproximadamente metade do tempo de duração da antibioticoterapia, o que justifica a repetição da coleta do LCR com a finalidade de avaliação da eficácia da terapia e de confirmação do prognóstico estabelecido.
O número de hemácias/ $\mu \mathrm{L}$ de $\mathrm{LCR}$ variou de zero a três em cinco amostras no M1 e de zero a quatro em quatro amostras no M2. Embora o número de hemácias/ $\mu \mathrm{L}$ de LCR observado em uma amostra no M1 (25 hemácias/ $\mu \mathrm{L})$ e em duas amostras no M2 (12 e 38 hemácias $/ \mu \mathrm{L}$ ) tenha sido maior, esses três animais foram mantidos no experimento, uma vez que Hurt e Smith (1997) consideraram que a presença de hemácias (dentro do intervalo de até $13.200 / \mu \mathrm{L}$ ) por contaminação iatrogênica em cães parece não interferir na contagem de leucócitos. Corroborando esse princípio, Stokol et al. (2009) avaliaram o LCR de 102 bovinos com doenças do $\mathrm{SNC}$ e só descartaram amostras que apresentaram contaminação com sangue acima de 50.000 hemácias $/ \mu \mathrm{L}$, justificando a inclusão de todas as amostras do presente estudo, visto que o maior valor foi de 38 hemácias $/ \mu \mathrm{L}$.

As contagens médias das células nucleadas dos animais (Tab. 1) apresentaram diferença significativa entre os dois momentos $(\mathrm{P}=0,0411)$. Entretanto, ambas se mantiveram dentro do intervalo de normalidade para a espécie (0-10 células/ $\mu \mathrm{L}$ ) (Stöber, 1993). Para Tvedten (1987), a conclusão mais importante que pode ser obtida pela análise do LCR é a presença de inflamação, que é primariamente caracterizada por pleocitose, fato que não ocorreu neste estudo.

Tabela 1. Valores médios e desvios-padrão da contagem total e diferencial das células nucleadas e dos teores de proteína $(\mathrm{mg} / \mathrm{dL})$ das amostras do líquido cefalorraquidiano coletadas em dois momentos (M1 e M2), com intervalo de 96 horas, de bovinos saudáveis

\begin{tabular}{c|c|c}
\hline \multirow{2}{*}{ Parâmetros } & M1 & Momentos \\
\cline { 2 - 3 } & $2,37 \pm 1,75 \mathrm{a}$ & $3,81 \pm 1,02 \mathrm{~b}$ \\
Células nucleadas (células/ $\mu \mathrm{L})$ & $70,33 \pm 7,28 \mathrm{a}$ & $52,00 \pm 17,65 \mathrm{~b}$ \\
Linfócitos (\%) & $29,67 \pm 7,28 \mathrm{a}$ & $47,08 \pm 17,55 \mathrm{~b}$ \\
Células mononucleares (\%) & $13,17 \pm 3,78 \mathrm{a}$ & $22,25 \pm 8,73 \mathrm{a}$ \\
Proteínas totais (mg/dL) &
\end{tabular}

Médias com letras minúsculas em uma mesma linha, seguidas de letras diferentes, diferem entre si $(\mathrm{P}<0,05)$.

O exame citológico do LCR deve ser realizado sempre, independentemente de a contagem total de células nucleadas ter sido normal (Tvedten, 1987). O LCR de bovinos sadios contém principalmente células mononucleares e corresponde a uma mistura de linfócitos e grandes células mononucleares (Stöber, 1993). Embora a contagem diferencial das células nucleadas do LCR no M1 estivesse dentro dos padrões normais, com predomínio dos linfócitos seguido por células mononucleares indiferenciadas, observou-se redução e aumento significativos $\quad(\mathrm{P}=0,0004 \quad \mathrm{e} \quad \mathrm{P}=0,0005$, respectivamente) para esses tipos celulares entre os dois momentos avaliados (Tab. 1). Além disso, a média de linfócitos na segunda coleta foi 


\section{Cunha et al.}

menor que o valor de referência (60-80\%) (Stöber, 1993). O contrário foi observado nas células mononucleares (20-40\%) (Stöber, 1993). Entretanto, as porcentagens de células mononucleares e linfócitos podem variar dependendo da técnica utilizada para a preparação citológica (Freeman e Raskin, 2003). Além desses achados, foi observado um pequeno número de neutrófilos e de eosinófilos no LCR no M2 (Tab. 2), como esperado no LCR de animais sadios (Welles et al., 1992).

Tabela 2. Valores medianos (Med.), máximos (Máx.) e mínimos (Mín.) do diferencial das células nucleadas das amostras do líquido cefalorraquidiano coletadas em dois momentos (M1 e M2), com intervalo de 96 horas, de bovinos saudáveis

\begin{tabular}{ccccccc}
\hline \multirow{2}{*}{ Parâmetros } & \multicolumn{7}{c}{ Momentos } \\
\cline { 2 - 7 } & Med. & Máx. & Mín. & Med. & Máx. & Mín. \\
\cline { 2 - 7 } & $1,00 \mathrm{a}$ & 20 & 0 & $2,50 \mathrm{a}$ & 38 & 0 \\
Hemácias (células $/ \mu \mathrm{L})$ & $0,00 \mathrm{a}$ & 0 & 0 & $1,00 \mathrm{~b}$ & 2 & 0 \\
Neutrófilos $(\%)$ & $0,00 \mathrm{a}$ & 0 & 0 & $0,00 \mathrm{a}$ & 1 & 0 \\
Eosinófilos $(\%)$ &
\end{tabular}

Medianas com letras minúsculas em uma mesma linha, seguidas de letras diferentes, diferem entre si $(\mathrm{P}<0,05)$.

Os níveis médios de proteínas totais liquóricas não apresentaram diferença significativa entre os dois momentos avaliados $(\mathrm{P}=0,0583)$. Além disso, os valores dos dois momentos permaneceram dentro do intervalo de referência (valores inferiores a $40 \mathrm{mg} / \mathrm{dL}$ ) de acordo com Scott (1995) ou entre 10 e $40 \mathrm{mg} / \mathrm{dL}$, segundo Stöber (1993).

Avaliações clínicas foram realizadas diariamente durante todo o experimento e até sete dias após a segunda coleta e nenhuma alteração clínica foi observada nesses animais.

\section{CONCLUSÃO}

Os resultados do presente estudo sugerem que a coleta consecutiva de líquido cefalorraquidiano, com intervalo de quatro dias entre elas, não induz inflamação local e alteração dos parâmetros citológicos e bioquímicos do LCR. Essa informação é importante devido à necessidade de monitorar a evolução do quadro clínico e/ou avaliar a eficácia do tratamento estabelecido em casos de doença neurológica.

\section{AGRADECIMENTOS}

À Capes, pela bolsa PICDT de doutorado, concedida ao primeiro autor; ao $\mathrm{CNPq}$, pela bolsa de produtividade ao último autor; e à Fapesp (2006/05836-6), pelo apoio financeiro.

\section{REFERÊNCIAS}

BELLINO, C.; MINISCALCO, B.; BERTONE, I. et al. Analysis of cerebrospinal fluid from cattle with central nervous system disorders after storage for 24 hours with autologous serum. BMC Vet. Res., v.11, n.201, 2015.

BRAUN, U.; ATTIGER, J. Ultrasonographic examination of the spinal cord and collection of cerebrospinal fluid from the atlanto-occipital space in cattle. Vet. Clin. Food Anim., v.32, p.109-118, 2016.

D'ANGELO, A.; MINISCALCO, B.; BELLINO, C. et al. Analysis of cerebrospinal fluid from 20 calves after storage for 24 hours. Vet. Rec., v.18, p.491-493, 2009.

DE LORENZI, D.; MANDARA, M.T. The central nervous system. In: RASKIN, R.E.; MEYER, D.J. Canine and feline cytology. A color atlas and interpretation guide. 2.ed. St. Louis: Saunders Elsevier, 2009. p.325-363.

FEITOSA, F.L.F. Semiologia veterinária: a arte do diagnóstico. 3.ed. São Paulo: Roca, 2014. $627 \mathrm{p}$.

FREEMAN, K.P.; RASKIN, R.E. Citologia do sistema nervoso central. In: RASKIN, R.E.; MEYER, D.J. Atlas de citologia de cães e gatos. São Paulo: Roca, 2003. p.275-308.

HOLBROOK, T.C.; WHITE, S.L. Ancillary test for assessment of the nervous system. Vet. Clin. N. Am. Food Anim. Pract., v.8, p.305-316, 1992. 
HURT, A.E.; SMITH, M.O. Effects of iatrogenic blood contamination of results of cerebrospinal fluid analysis in clinically normal dogs and dogs with neurological disease. J. Am. Vet. Med. Assoc., v.211, p.866-867, 1997.

KUMAR, V.; KUMAR, N. Diagnostic value of cerebrospinal fluid evaluation in veterinary practice: an overview. J. Adv. Vet. Res., v.2, p.213-217, 2012.

MAYHEW, I.G. Large animal neurology: a handbook for veterinary clinics. London: Lea \& Febiger, 1989. 379p.

SAMPAIO, I.B.M. Estatística aplicada à experimentação animal. Belo Horizonte: UFMG, 1998. 221p.

SCOTT, P.R. Diagnostic techniques and clinicopathologic findings in ruminant neurologic disease. Vet. Clin. N. Am. Food Anim. Pract., v.20, p.215-230, 2004.

SCOTT, P.R. The collection and analysis of cerebrospinal fluid as an aid to diagnosis in ruminant neurological disease. Br. Vet. J., v.151, p.603-614, 1995.
ST. JEAN, G.; YVORCHUCK-ST. JEAN, K.; ANDERSON, D.E.; MOORE, W.E. Cerebrospinal fluid constituents collected at the atlanto-occipital site of xylazine hydrochloride sedated, healthy 8-week-old Holstein calves. Can. J. Vet. Res., v.61, p.108-112, 1997.

STÖBER, M. Sistema nervoso central. In: ROSEMBERGER, G. Exame clínico dos bovinos. Rio de Janeiro: Guanabara Koogan, 1993. $421 \mathrm{p}$.

STOKOL, T.; DIVERS, T.J.; ARRIGAN, J.W.; MCDONOUGH, S.P. Cerebrospinal fluid findings in cattle with central nervous system disorders: a retrospective study of 102 cases (1990-2008). Vet. Clin. Pathol., v.38, p.103-112, 2009.

TVEDTEN, H.W. Clinical pathology of bovine neurologic disease. Vet. Clin. N. Am. Food Anim. Pract., v.3, p.25-44, 1987.

WELLES, E.G.; TYLER, J.W.; SORJONEN, D.C.; WHATLEY, E.M. Composition and analysis of cerebrospinal fluid in clinically normal adult cattle. Am. J. Vet. Res., v.53, p.2050-2057, 1992. 